\title{
DIE KOMMUNISTIESE STAATSTEORIE EN -PRAKTYK
}

Die kommunisme is ' $n$ besondere uitloper van die universalistiese uitgangspunt in die wysbegeerte. Aan die hand van sy fundamentele grondslag kan die kommunisme nader tipeer word as ' $n$ variasie van die sogenaamde staatlike sosialisme. Hierdie tipering verg vervolgens verduideliking.

Een van die fundamenteelste wysgerige probleemstellinge betref die verhouding tussen die algemene (universele) en besondere (individuele) dinge in die werklikheid: die verhouding van die sand tot die woestyn (stof); van die boom tot die bos (plant); van die skaap tot die kudde (dier); of van die enkeling tot die staat (mens). Ten opsigte van hierdie probleem leer die universalisme dat die universele dinge die belangrikste is en dat die individuele dinge slegs 'n afgeleide bestaan voer - teenoor die individualisme wat voorkeur gee aan die individuele dinge as sou die universele slegs 'n naam of 'n begrip wees sonder enige realiteit in die werklikheid. Die standpunt dat die mens slegs in 'n sosiale verhouding met sy medemens kan bestaan en in verband daarmee, dat die mens by uitnemendheid 'n sosiale wese is, is ' $n$ treffende voorbeeld van universalisme.

Die universalisme lê ten grondslag van talryke relatief onderskeibare, maar ook wesentlik verskillende wysgerige opvattinge. Op die gebied van die natuurwetenskap kom dit onder meer tot uiting in die holisme van Smuts; op kenteoretiese gebied het dieselfde uitgangspunt in 'n heel ander sin sy stempel afgedruk op die Middeleeuse universalia-vraagstuk, ens., ens. Maar die universalisme sprei sy vleuels ook oor die hele terrein van die humaniora; die talryke verskyningsvorme van die veelvuldige soorte verhoudinge waarin elke mens hom met sy medemens verbonde weet. In die onderhawige sin van die woord beteken die sosialisme nou daardie vertakking van die universalisme, wat op die terrein van menseverhou- 
dinge die universele dinge bevoorreg ten koste van die individuele mens.

Die sosialisme leen hom egter verder meer tot verskeie variasies na mate in die rangorde van individue en sosiale verbindinge van individue die vernaamste plek toegeken word aan byvoorbeeld die kerk (kerklike sosialisme) soos in die gangbare Rooms-Katolieke denke; of aan die nasie (nasionaal-sosialisme) soos in die politieke belydenis van die Hitler-bewind in Duitsland, of an die staat (staatlike sosialisme) soos in die huidige staatlike bedeling van dic Unie van Sosialistiese Sowjet-Republieke (U.S.S.R.)

Die staatlike sosialisme wat aan die kommunisme ten grondslag lê (teenoor ander vorme van staatlike sosialisme) vertoon oorwegend 'n ekonomiese karakter. Want vir die kommunisme gaan dit hoofsaaklik om die volkome beskikking van die staat oor alle produksiemiddele en verbruikersgoedere. As sodanig is die kommunisme egter nie net 'n ekonomies gekleurde staatsleer nie, want die Marxisme laat die invloed van sy basiese belydenis op alle terreine van die lewe geld. Dit beoog naamlik om langs die weg wat hy voorstaan eventueel alle maatskaplike klasse-verskille tussen mense uit te skakel en beskou die volkome oppergesag van die staat oor alle samelewingsverbande, soos die kerk, skool en gesin as 'n noodsaaklike voorwaarde vir die verwerkliking van die sosialistiese utopia. Daarom word die staatlike verband bevoorreg bo die individuele bestaan en lewe van die enkeling, en word die staatsgesag in absolute sin verhef bo enige wilsbesluit hoegenaamd van sowel die individuele staatsonderdane as die ander (nie-staatlike) samelewingsverbande.

Dit kan verder gekonstateer word dat die kommunisme gegrond is op en inspirasie put uit die minderbevoorregting van die arbeidersklasse; en ten slotte dat die kommunisme hom beywer om die ganse wêreld te verower langs die weg van revolusie.

Die bostaande riglyne is gegrond deels op die huidige teorie van die wysgerige eksponente van die kommunisme 
en deels op die hedendaagse politieke praktyk in die U.S. S.R. en ander kommunistiese moondhede. Die aandagtige toehoorder sou wel agtergekom het dat my analise in verskeie opsigte oënskynlik nie strook met die leerstellinge van Karl Marx self nie; en dit juis met betrekking tot daardie aspekte wat in die onderhawige verband ten seerste ter sake is, naamlik die funksie van die kommunistiese staat.

Karl Marx was naamlik die mening toegedaan dat die staat ' $n$ bose instelling is wat spruit uit die klasse-onderskeid, wat weer op sy beurt 'n noodsaaklike aanhangsel van die kapitalisme is. Die staatlike reg, sê hy, is 'n ewe verwerplike middel waarmee die kapitaliste die arbeiders uitbuit. Die menslike samelewing wat hy in die eventuele vooruitsig gestel het en wat bestem is om die ganse mensdom te omvat, sou daarom volgens hom geen staat wees nie en na gelang alle vorme van klasseverskille sal verdwyn, sal die reg sogenaamd ook wegkwyn. Sy argumentasie verloop min of meer soos volg:

Binne die raamwerk van die positivisme van sy tyd en teen die agtergrond van die ongesonde en ondraaglike maatskaplike toestande van destyds, wat veral uit die Industriële Revolusie voortgespruit het, het Karl Marx die opkoms en opheffing van die minderbegunstigde werkersklas bepleit en voorspel. Die oorsaak van die stryd tussen werkgewer en arbeider, kapitalis en proletariaat is, volgens Marx, die stande- of klasseverskil, wat op sy beurt weer voortspruit uit arbeidspesialisasie en privaat eiendomsreg. Die klassestryd sal volgens hom uitloop op 'n wêreldrevolusie, wat deur die proletariaat gewen en waardeur die sogenaamde diktatuur van die proletariaat gevestig sal word. Onder leiding van dic proletariese diktatuur sal alle produksiemiddele tot eiendom van die staat gemaak en enige vorm van privaat eiendomsreg verbied word. Namate die grense tussen werkgewer en werknemer sodoende sal verdwyn en alle klasseverskille geëlimineer sal word, sal die behoefte aan 'n owerheidsgesag en positiewe regsreëlings ook in die niet verdwyn. 
Dan sal die mensdom sogenaamd volkome vreedsaam saambestaan.

Tot dusver kon die kommunisme sonder veel inspanning reeds sy vleuels span oor 'n deel van ons aarde wat meer as 'n derde van die totale wêreldbevolking huisves en wat verreweg die grootste gebied van Oos-Europa en Asië insluit; van die oorgrens van Wes-Duitsland, Oostenryk en Italië (maar met uitsluiting van Suid-Korea, Japan, Formosa en die Fiiippynse eilande) in die ooste; en van die noordelike grense van Griekeland, Turkye, Iran, Afghanistan, Kashmir, Nepal, Bhutan, Burma, Laos en Suid-Vietnam in die suide, tot aan die verste uithoek van die aarde in die noorde. En nie lank gelede nie het die kommunisme met dic ideologiese verowering van Kuba 'n vastrapplek gekry op die drumpel van sy grootste struikelblok, die Verenigde State van Amerika: Die jongste toevoeging tot die geledere van die kommunistiese blok het op 12 Januarie van hierdie jaar plaasgevind toe die regering van sjeik Mohammed Shamti van Zanzibar slegs 'n maand na sy onafhanklikheidswording, met behulp van 'n staatsgreep onder leiding van veldmaarskalk John Okello omvergewerp is.

Dit sou my te ver van die opset van hierdie voordrag wegvoer as ek enigsins op die ontstellende geskiedenis van die kommunistiese verowering ingaan. Laat dit voldoende wees om hier slegs kortweg te konstateer dat die kommunisme dit tot dusver nie verder in die praktyk kon bring as om slegs die sogenaamde diktatuur van die proletariaat te grondves nie. Alles dui daarop dat die staatlose en reglose samelewing wat Karl Marx in die eventuele vooruitsig gestel het, ook vir daardie lande wat reeds die kommunisme aanvaar het, nog in die heel verre toekomstige verskict lê. Die mening word trouens toenemend in die geledere van die hedendaagse kommunistiese eksponente self gehuldig dat hierdie utopia nie gou nie en waarskynlik nooit verwesenlik sal kan word nie.

Die laasgenocmde insig is besig om 'n radikale ommeswaai in die staats- en regsleer van die kommunisme te weeg te bring. Na mate die besef posvat dat die kom- 
munisme nie daarin sal kan slaag om die staatlike verband te vernietig nie en dat die reg 'n noodwendige en blywende modale aspek van die skepping is, kan die kommunisme vanselfsprekend nie die Marxistiese antipatie ten opsigte van die staat en reg bly handhaaf nie. Vandaar die tendens binne dic kommunisme om die kontemporêre politieke bedeling in die U.S.S.R. met sy ekonomies gekleurde staatsabsolutisme as die ideale voor te hou. Op hierdie opvatting, dat die U.S.S.R. soos dit vandag daar uitsien die omega, die eindpunt van die dialektiese ontwikkelingsgang van die staatkundige wêreldgeskiedenis is en nie op die Marxistiese utopie van 'n staatlose en reglose menslike samelewing nie, is die samevattende tipering van die kommunisme wat ek ter inleiding gegee het, gefundeer.

In hierdie verband kan terloops vermeld word dat die huidige tweespalt tussen die U.S.S.R. aan die een kant en Kommunistiese China aan die ander kant juis op hierdie vraagstuk betrekking het. Want terwyl mnr. Kroesjtsjef tevrede is om ten minste lippediens te bewys aan die gekoesterde ideaal van vreedsame naasbestaan met die Weste en om hoogstens die politieke praktyk van die U.S.S.R. as die ideale staatsleer te propageer, eis Chou En-Lai dat daar spoed gemaak moet word met die vestiging van die proletariese diktatuur oor die ganse aardbol, en wel langs die bloedige weg van revolusie, en koester hy met ongeduld die ideaal dat die staatlose en reglose samelewing binne die afsienbare tyd verwerklik moet word.

Ek het gesê dat die oorspronklike antipatie van Karl Marx ten opsigte van die staat en reg geleidelik plek moes maak vir ' $n$ meer verligte opvatting in hierdie verband. Die eerste spore van hierdic ontwikkeling is reeds by Marx en Engels self aan te wys. Alhoewel Engels byvoorbeeld volgehou het dat die staat - hy bedoel eintlik die staatsgesag - eventueel sou wegkwyn, het hy tog later iets, met die gebruik van uiters vae terminologie, in die plek daarvan gaan stel. "The government of people", sê hy, ,is replaced by the administration of things and the direction of the process of production". In die plek van 
die regeringsorganisasie kom 'n ander organisatoriese werksaamheid. Prakties kom dit daarop neer dat die staat omskep word in 'n magistrale sake-onderneming en dat die politieke administrasie omgevorm word tot 'n ekonomiese organisasie.

Die weg vir die kommunisme om groter waardering te kan hê vir die staat en reg is egter hoofsaaklik deur die toedoen van mense soos Karl Renner geopen. Aan die hand van die konsep van eiendomsreg het Renner, 'n Oostenrykse sosialis, met waardering getuig van die sosiale funksie van die reg. Hy het trouens uitdruklik 'n beroep op sy sosialistiese geesgenote gedoen om hulle antipatie teen die reg te laat vaar. Die reg as sodanig het die mag om sosiale omstandighede te beïnvloed en kan, as dit in die regte vorm gegiet word, meehelp om die sosialistiese ideaal te verwesenlik.

Aan die ander kant hou kommunistiese skrywers soos Pashukanis egter vol dat staatsgesag en positiewe reg ' $n$ instrument van onderdrukking in die hande van kapitaliste is en dat dit daarom eventueel onder die vaandel van die kommunisme sal verdwyn.

Terwyl die kommunistiese teoretici die vraag aangaande die doenlikheid of ondoenlikheid van staat en reg met die geskrewe woord probeer oplos, gebruik die U.S.S.R.-staat die dwingende gesag van die reg om die diktatuur van die proletariaat stewig in die saal te hou. Die verskoning word aangevoer dat die proletariese diktatuur genoodsaak is om van die kapitalistiese middele gebruik te maak ten einde die kommunisme te handhaaf. Die mag van die diktatuur moet met behulp van allerlei dwingende regsvoorskrifte gegrondves en verstewig word ten einde die aankoms van die kommunistiese utopia te verseker en te bespoedig. In dié gees het Vishinsky, die destydse Minister van Buitelandse Sake van die U.S. S.R., in 1938 die reg gedefinieer as: "the corpus of rules of behaviour expressing the will of the ruling class, established by legislation, and also of custom sanctioned by the State and secured by its coercive power in order to 
protect, to strenghten and to develop such social relations as are favourable for the ruling class". (Ek kursiveer).

Om tot sover saam te vat kan net weer die volgende gestel word:

Karl Marx en sy geesverwante vriend, Friedrich Engels, was die mening toegedaan dat die staat en die staatlike reg ' $n$ instrument in die hande van die kapitaliste is, met behulp waarvan die arbeiders uitgebuit word. Teenoor hierdie verbete antipatie gaan daar in kommunistiese kringe toenemend stemme op wat 'n groter waardering vir die staat en die reg bepleit. Laasgenoemde spruit onder meer uit die feit dat die U.S.S.R. sy staatlike ower heid met absolutistiese mag beklee en dat die reg as ' $n$ noodsaaklike middel vir die bestendiging van die kommunisme aangewend word; en gepaard daarmee, die insig dat die vestiging van die staatlose en reglose kommunistiese utopia 'n onpraktiese ideaal is. Die kommuniste besef naamlik toenemend dat die wêreld nouliks verder kan vorder as die sogenaamde proletariese diktatuur soos dit tans in die U.S.S.R. funksioneer. 'n Absolutistiese staatsgesag met ingrypende regsvoorskrifte blyk 'n noodsaaklike voorwaarde vir en intrinsieke bestanddeel van die kommunistiese diktatuur te wees.

Laat ons daarom nie verder besin oor die Marxistiese hersenskim van 'n staatlose en reglose menslike samelewing nie, maar laat ons vervolgens eerder die staatspraktyk onder die diktatuur van die proletariaat, soos ons dit vandag in die U.S.S.R. aantref, globaal onder oë neem.

Die kommunisme is gebou op die geloof in die boosheid van 'n standsverskil wat op ekonomiese oorweginge gefundeer is. In sy grondwet lees ons dat die Unie van Sosialistiese Sowjet-Republieke (U.S.S.R.) 'n sosialistiese staat is van werkers en landbouers (artikel 1) en dat die politieke grondslag van die U.S.S.R. gegroei en sterk geword het ,as a result of the overthrow of the power of the landlords and capitalists and the conquest of the dictatorship of the proletariat" (artikel 2).

Dit verg geen vergesogte verbeelding nie om in te sien dat daar reeds in die uitgangspunt van die magtige kom- 
munistiese staat 'n innerlike dualisme opgesluit lê: aan die een kant die verbod op 'n standsverdeling en aan die ander kant die mag van die ,diktatuur van die proletariaat". Want alhoewel die U.S.S.R.-grondwet uitdruklik alle mag aan die ",working people of town and country" toeken (artikel 3), word daardie mag uitgeoefen deur verteenwoordigers wat diktatoriaal kan optree. Ten einde laasgenoemde te illustreer word vervolgens kortliks stilgestaan by die verwerkliking van die kommunisme op die gebied van enkele fasette van die lewensfeer. En om die deur die propagandamotief geïnspireerde skyn te vermy, wat opgesluit lê in die berigte aangaande die U.S.S.R. wat in die Westerse Wêreld vrygestel word, laat ons sover moontlik die U.S.S.R.grondwet vir homself spreek. Vir dié doel word gebruik gemaak van die Engelse vertaling van die grondwet soos dit deur F. L. Schuman: Government in the Soviet Union, 1962, bl. 168-187, weergegee word.

A. Staatkundig: Die hoogste staatlike orgaan in die U.S.S.R. is die sogenaamde Opperste Sowjet (artikel 30), wat onder die dekmantel van 'n "diktatuur van die proletariaat" met bykans onbeperkte mag beklee word (vgl. artikel 31, saamgelees met artikel 14). Veral opvallend is die ingrype van die Opperste Sowjet in die ekonomiese en maatskaplike lewensfere. Hierdie owerheidsorgaan is byvoorbeeld beklee met die reg om:

(i) banke, industriële ondernemings en landboukundige instellings te administreer;

(ii) vervoer- en kommunikasiemiddele te beheer;

(iii) monetêre en kredietstelsels te bestuur;

(iv) staatsversekering te organiseer;

(v) lenings toe te staan;

(vi) die basiese beginsels van onderwys en openbare gesondheid te bepaal; en

(vii) regsbeginsels aangaande die huweliks- en familielewe neer te lê; ens.

Die mag van die regeringsliggaam blyk verder daaruit dat ' $n$ lid daarvan nie sonder die tocstemming van die 
Opperste Sowjet gearresteer of regtens vervolg mag word nie (artikel 52).

Die Opperste Sowjet bestaan uit twee kamers (artikel 33), naamlik:

(a) die sogenaamde "Soviet of the Union", wat deur die landsburgers verkies word op die basis van een verteenwoordiger vir elke 300,000 lede van die bevolking (artikel 34); en

(b) die sogenaamde "Soviet of Nationalities", wat uit afgevaardigdes van die ledestate van die U.S.S.R. ooreenkomstig 'n voorgeskrewe getalsverhouding bestaan (artikel 35).

Die twee kamers besit gelyke regte (artikel 37 ), ook met betrekking tot die indiening van wetsontwerpe (artikel 38).

As die Opperste Sowjet nie in sitting is nie, val sy magte op die skouers van die sogenaamde Presidium van die Opperste Sowjet; 'n liggaam wat in 'n gesamentlike sitting van die twee huise, deur die Opperste Sowjet saamgestel word (artikel 48) en aan laasgenoemde verantwoording verskuldig is en wat origens met wye administratiewe bevoegdhede beklee is (artikel 49).

Die onderskeie staatlike bevoegdhede van die U.S. S.R. sien soos volg daar uit:

(i) Die wetgewende gesag berus uitsluitlik in die hande van die Opperste Sowjet (artikel 32), wat vir dié doel ten minste twee maal per jaar vergader, maar as dit volgens die diskresie van die Presidium of van 'n ledestaat nodig blyk, ook 'n buitengewone sitting moet hou (artikel 46). Wetgewing vereis 'n gewone meerderheid in albei huise van die Opperste Sowjet (artikel 39), maar vir 'n wysiging van die konstitusie is 'n tweederde-meerderheid in elke huis nodig (artikel 146). As die twee huise oor ' $n$ bepaalde aangeleentheid nie tot eenstemmigheid kan kom nie, word die saak verwys na 'n gesamentlike kommissie van die twee huise en as laasgenoemde nie eenstemmigheid kan bereik nie, word dit nogmaals terugverwys vir heroorweging deur die twee huise. Indien daar dan nog nie 'n oplossing gevind kan word nie, word 
die Opperste Sowjet deur die Presidium ontbind en ' $n$ nuwe verkiesing gereël (artikel 47).

(ii) Die uitvoerende gesag word opgedra aan 'n kabinet („Council of Ministers"), wat saamgestel word deur die Opperste Sowjet in 'n gesamentlike sitting van die twee huise (artikel 64, saamgelees met artikels 56 en 70). Die besluite en bevele van die Ministers is oor die hele land bindend (artikel 67), maar enigeen daarvan kan deur die Presidium van die Opperste Sowjet nietig verklaar word (artikel 49 (f)). Die Ministers is oor die algemeen verantwoording verskuldig aan die Opperste Sowjet (artikel 65).

(iii) Die regterlike gesag word uitgeoefen deur' 'n aantal geregshowe met die Hooggeregshof aan die spits (artikel 102). Die regters van laasgenoemde word deur die Opperste Sowjet benoem. Die grondwet maak ook voorsiening vir 'n sogenaamde „People's Court" met regters wat deur die burgers van die betrokke distrik verkies word (artikel 109). Behalwe in uitsonderingsgevalle wat deur spesiale wetgewing gereël word, moet die regters in elke saak bygestaan word deur ,assessore van die volk" (artikel 103).

Die regters is volgens artikel 112 onafhanklik ,and subject only to the law", maar daardie "onafhanklikheid" word in twee opsigte ingrypend beperk:

(a) Die wette van die U.S.S.R. word nie deur die hof nie, maar deur die Presidium van die Opperste Sowjet uitgelê of geïnterpreteer (artikel 49 (c)).

(b) Die regters word vir 'n tydperk van slegs vyf jaar aangestel of in die geval van die "People's Court", verkies. As 'n regter dus 'n "ongewenste" uitspraak sou gee, loop hy gevaar om nie herbenoem te word nie.

Die onderskeie republieke wat lede is van die U.S. S.R., word huishoudelik soortgelyk geadministreer, maar hulle grondwet, Sowjet, Ministers en regbanke is ondergeskik aan dié van die U.S.S.R.

Stemreg word op die basis van een man, een stem (artikel 136) toegeken aan alle burgers van 18 jaar en 
ouer ,irrespective of race or nationality, sex, religion, education, domicile, social origin, property status or past activities", behalwe diegene wat amptelike kranksinnig verklaar is (artikel 135). Enige burger wat 23 jaar of ouer is, kan verkies word. Hierdie blyke van demokrasie is egter sinsbedrog, want die keuse van die volk is beperk tot kandidate van dieselfde politieke party. Artikel 141 van die grondwet bepaal naamlik dat slegs die Kommunistiese Party-organisasie, vakbonde, koöperatiewe verenigings, jeugbewegings en kulturele organisasies die bevoegdheid sal hê om kandidate te benoem. Dit geld vir die verkiesing van alle publieke liggame wat deur die stemming van die volk saamgestel word. Op dié manier verseker die kommunisme onder die dekmantel van demokrasie, die eliminering van alle opposisie in elke samelewingsverband.

B. Ekonomies. Die ekonomiese grondslag van die U.S.S.R. word in artikel 4 van die grondwet beskryf as ,the socialist system of economy and the socialist ownership of the instruments and means of production, firmly established as a result of the liquidation of the capitalist system of economy, the abolition of private ownership of the instruments and means of production, and the elìmination of the exploitation of man by man". Dit beteken prakties dat die hele ekonomiese orde sentraal beplan en bestuur word deur die Opperste Sowjet, of as hy nie in sitting is nie, die Presidium van die Opperste Sowjet; dat in die plek van die privaat eienaar, die staat gekom het; en dat die staat in plaas van die privaat kapitalis, die werkgewer van die arbeiders is. Kortom, die U.S.S.R. is niks anders nie as ' $n$ omvattende handelsmaatskappy en as daar in die kapitalisme noodwendig sprake moet wees van "the exploitation of man by man", dan beteken die kommunisme eksploitasie van die mens deur die staat. Want Lenin en sy opvolgers het nie die werkgewer -werknemersverhouding tot niet gemaak nie, hulle het slegs in die plek van die privaat werkgewer 'n ander kapitalis gestel, naamlik die staat.

Die U.S.S.R.-grondwet beskryf graag die staat as die 
„working people of town and country" (vgl. artikel 3) en staatseiendom as ,property belonging to the whole people" (vgl. artikel 5). Dat die burgers die substraat van 'n staat uitmaak is sekerlik waar. Maar in die U.S.S.R. is dit ook so dat die mag uitgeoefen word en die eiendom beheer word deur 'n handjievol verteenwoordigers van die volk in die Opperste Sowjet, wat met diktatoriale magte en bevoegdhede beklee is. Prakties kom dit dus daarop neer dat die Opperste Sowjet en gedurende die reses van laasgenoemde, die Presidium, die eienaar, ondermeer en werkgewer in die U.S.S.R. is. Laasgenoemde word voldoende bevestig deur die kommunistiese konsep van eiendomsreg en arbeid.

(1) Eiendomsreg: Gesien van die kant van die eienaar, maak die U.S.S.R.-grondwet onderskeid tussen die volgende soorte eiendom:

(a) Staatseiendom: Volgens artikel 6 is die staat die eienaar van die land, minerale rykdom, waters, bosse, meulens, fabrieke, myne, die spoorweë, water- en lugvervoer, banke, kommunikasiestelsels, staatlik georganiseerde landbouondernemings (staatsplase, -masjinerie, -trekkerhawens, ens.), munisipale ondernemings en die meerderheid van woonhuise in die stede en industriële sentra.

(b) Koöperatiewe en kollektiewe plaaseiendom: Die kollektiewe plase en koöperatiewe verenigings is volgens artikel 7 die eienaars van hulle onderskeie plase en organisasies, asook die lewende hawe, implemente, produkte en geboue wat daarmee saamgaan. Nogtans vind die wetgewer dit nodig om uitdruklik die grond van die kollektiewe plase aan laasgenoemde te waarborg vir hulle langdurige en gratis gebruik (artikel 8). Dit skep die indruk dat die kollektiewe boere inderdaad nie die (gesamentlike) eienaar van die grond is nie, want anders is so ' $n$ waarborg mos nie nodig nie. Die betrokke voorskrif is in elk geval in stryd met die ongekwalifiseerde verklaring in artikel 6 dat die land staatseiendom is.

(c) Privaat eiendom: Die grondwet erken die bestaan van en belowe regsbeskerming vir die persoonlike 
eiendomsreg van die burgers ten opsigte van hulle inkom ste uit werk, woonhuise, huishoudelike benodigdhede produkte van huishoudelike bedrywe, artikels vir persoonlike gebruik en gerief en enige erfgoed (artikel 9 en 10 ).

Elke huishouding op 'n kollektiewe plaas kry verder - naas hulle eiendomsreg op huishoudelike benodigdhede, 'n woonhuis, lewende hawe, pluimvee en 'n geringe hoeveelheid (of die kleinere?) landboukundige implemente, - die gebruik van 'n klein plot (artikel 7).

(2) Arbeid: Elke burger van die U.S.S.R. het volgens die grondwet 'n reg om te werk en dus van werkloosheid gevrywaar te word (artikel 118). Maar arbeid is ook 'n plig: „Work in the U.S.S.R. is a duty and a matter of honour for every able bodied citizen, in accordance with the principle: ,He who does not work, neither shall eat'" (sic!) (artikel 12). Slegs diegene wat weens ouderdom, siekte of ander ongeskiktheid nie daartoe in staat is nie, word van werk gevrywaar (artikel 120).

Die voorgeskrewe werksure per dag word in artikel 119 soos volg uiteengesit: 8 uur vir industriële, kantooren professionele werkers; 7 tot 6 uur vir hardwerkende handelaars; en 4 uur vir klerke in winkels wat besonder bedrywig is. Die wet sê nie of dit maksimum of minimum werksure is nie, maar die aanhef van die artikel lui dat die burgers van die U.S.S.R. 'n reg het „to rest and leisure".

Dieselfde artikel lê verder die beginsel neer van 'n jaarlikse betaalde verlof vir industriële, kantoor- en professionele werkers, maar bepaal in dié verband niks aangaande ander soorte arbeiders nie; behalwe dat moeders geregtig is op kraamverlof teen volle betaling (artikel 122).

Met betrekking tot die omvang van die besoldiging vir arbeid, verval die wetboek in vae slagspreukterminologie. Die sosialistiese beginsel wat in dié verband geld, lui soos volg: "From each according to his ability, to each according to his work" (artikel 12). Dit beteken blykbaar: „payment for their work in accordance with 
its quantity and quality" (artikel 118). Dit wil dus voor. kom asof die U.S.S.R. afgesien het van die fundamentele grondslag van die sosialisme, naamlik dat almal gelyk besoldig word ongeag die aard (en omvang?) van sy arbeid en dat die rykdom van die land sodoende gelyk onder die burgers verdeel word. Dit is in elk geval redelik om aan te neem dat die werkgewer (die staat) geroepe is om oor die kwaliteit en kwantiteit van die arbeid te oordeel en dus die loon te bepaal. Dit is ook waarskynlik die staat wat die aanleg en vaardigheid van die burgers bepaal en daarom ooreenkomstig die genoemde ",sosialistiese" beginsel moet besluit watter werk deur wie gedoen moet word.

Want die U.S.S.R.-staat is ' $n$ magtige sake-onderneming en werkgewer. Ekonomies gesproke is die volk 'n instrument in sy hand, want die staat is eienaar van die fabrieke, myne, landbou- en bosboubedrywe en vervoeren kommunikasiestelsels (artikel 6); die staat voorsien die sanatoria (geneesinrigtings), vakansiegeriewe en klubs vir die werkers (artikel 119); die staat ontwikkel die sosiale versekering van industriële, kantoor- en professionele werkers op staatsonkostc en versorg (gratis) mediese dienste aan die arbeiders (artikel 120); die staat beheer die onderwysinrigtings, op die basis van "close links between school, and life and production" (artikel 121); die staat sorg vir kraaminrigtings en kleuterskole (artikel 122); die staat moet vergunning gee vir die gebruik van drukperse, openbare geboue en die strate (artikel 125); ens. En jy, mens, is verplig om by die sentraal geleide plan in te val en jou lot daarna te skik.

C. Maatskaplik: Ooreenkomstig die kommunistiese antipatie teen elke moontlike oorsaak van 'n standsonderskeid, bely die U.S.S.R.-grondwet die gelykheid van alle burgers van die staat ongeag hulle nasionaliteit of ras, ten opsigte van alle vertakkinge van die ekonomiese, staatkundige, kulturele, politieke en ander openbare bedrywighede. Die direkte of indirekte toekenning van enige besondere reg of voorreg op grond van rasse- of nasionaliteitsoorwegings, sowel as die verkondiging van 
'n rasse- of nasionale eksklusiwiteit of rassehaat, word uitdruklik strafbaar gestel (artikel 123). As die periodieke berigte oor die vernedering van Ghanese en ander Afrikastudente in die U.S.S.R. enigsins gegrond is, moet ons aflei dat die kommuniste òf nie baie eerlik is nie, òf hulle grondwet nie te ernstig opneem nie.

Ook die vryhede van die burgers staan in die U.S. S.R.-grondwet duidelik opgeteken, naamlik die vryheid van spraak, van die pers, van vergaderings en die vryheid om straatoptogte te hou en te betoog. Die pers, papier, openbare geboue, strate, kommunikasiemiddele en ander geriewe word deur die staat tot die beskikking van die werkers gestel, sodat laasgenoemde hierdie „vryhede" kan gebruik (artikel 125).

Op die voetspoor van die liberalisme, omskryf die grondwet ook 'n aantal regte van die burgers, te wete die reg om te werk (artikel 118); die reg om te ontspan (artikel 119); die reg op onderhoud gedurende siekte, ongeskiktheid of 'n hoë ouderdom (artikel 120); die reg op onderwys (artikel 121); die reg om aan 'n vakbond, koöperatiewe vereniging, jeugorganisasie, sportklub, verdedigingsorganisasie en 'n kulturele, tegniese of wetenskaplike vereniging te behoort; en die reg om by die Kommunistiese Party aan te sluit (artikel 126). Laasgenoemde reg word volgens die grondwet vrywillig uitgeoefen deur "the most active and politically-conscious citizins in the ranks of the working class, working peasants and working intelligentsia", want die Kommunistiese Party ,is the vanguard of the working people in their strugge to build communist society and is the leading core of all organizations of the working people, both public and state".

Die grondwet vrywaar ook die burgers teen ongeoorloofde arrestasie (artikel 127) en beskerm die privaatheid van hulle huise en korrespondensie (artikel 128). Aan vreemdelinge wat vervolg word weens hulle beskermende optrede in belang van die werkers, wetenskaplike 
aktiwiteite of stryd vir nasionale vrywording, word die reg van asiel beloof (artikel 129).

Anders as die liberalisme, ruim die U.S.S.R.-grondwet ook plek in vir die pligte van die burgers, byvoorbeeld die plig om te werk (artikel 12); die algemene plig om minstens agt jaar lank onderwys te ondergaan (in die moedertaal) (artikel 121); die plig om die landswette te gehoorsaam, arbeidsdissipline te eerbiedig, eerlik alle verpligtinge na te kom en die reëls van sosialistiese omgang uit te leef (artikel 130); die plig om die publieke sosialistiese (staats-) eiendom te beskerm (artikel 131); die plig om militêre diens te doen (artikel 132); en die heilige plig om die land te verdedig (artikel 133).

Laat dit vooraf beklemtoon word dat dit van nugtere insig getuig as jy die vryhede en regte van 'n landsburger omlyn met die grense van sy verpligtinge - eerder as om, soos die liberalisme, ongebonde vryhede en regte neer te lê en sodoende elke druppel aanvoeling met die eise van die praktyk uit die oog te verloor. 'n Mens leer die kommunisme ken nie deur eensydig op die regte en vryhede van die onderdane te let, of deur slegs die pligte van die volk te beklemtoon, soos Amerikaanse propagandiste graag doen nie, maar deur sowel die regte en vryhede as die pligte van die burgers in die regte perspektief te stel.

En dan is dit duidelik dat die vryhede en regte van die volk begrens word deur en uitgeoefen moet word binne die raamwerk van die belange van die U.S.S.R. oor die algemeen en die kommunisme in besonder. Daaroor laat die grondwet geen twyfel nie. Eers loof die grondwet die Kommunistiese Party (artikel 126); daarna maan dit die burgers om die grondwet en landswette te onderhou, arbeidsdissipline te gehoorsaam, sy publieke pligte eerlik na te kom en die reëls van sosialistiese omgang te eerbiedig (artikel 130); en vervolgens gelas die wet dat die sosialistiese eiendom beskerm en versterk moet word ,as the sacred and inviolable foundation of the Soviet system, as the source of the wealth and might of the country, as 
the source of the prosperity and culture of all the working people" (artikel 131). Wie die gebod nie gehoorsaam nie is "enemies of the people"; hy pleeg hoogverraad en is daarom strafbaar "with all the severity of the law as the most heinous of crimes".

Kortom, in die U.S.S.R. mag jy sê wat jy wil, skryf wat $\mathrm{jy}$ wil, betoog soos $\mathrm{jy}$ wil, aan ' $\mathrm{n}$ vereniging behoort as jy wil en oor die algemeen doen wat jy wil - solank $\mathrm{jy}$ in geen opsig die kommunisme skaad nie. Elke aanslag teen die staatsgesag of landsbeleid (soos dié van 'n paar jaar gelede in Hongarye) word met die uiterste geweld onderdruk.

D. Godsdiens: Die U.S.S.R.-grondwet magtig in dieselfde asem sowel godsdiensvryheid as anti-godsdienstige propaganda. Die kerk word uitdruklik geskei van die staat, asook die skool van die kerk (artikel 124). Alle inligting dui daarop dat die propagandiste teen die godsdiens in Rusland die oorhand verkry oor alle vorme van religie. Dit is bekend dat Karl Marx 'n geswore ateïs was en dat hy hom in geen onsekere taal teen die godsdiens uitgespreek het nie. Hy beskryf die godsdiens byvoorbeeld as die opium van die volk en leer dat die mensdom in sy utopia gerieflik daarsonder kan klaarkom.

Dit staan egter nie vas of en in hoeverre die godsdiens in die kommunistiese wêreld feitelik onderdruk word nie, maar daar bestaan geen redelike twyfel dat die beoefening daarvan beslis ontmoedig en by veral die jeug bespotlik voorgestel word nie. Want in die plek van God en die godsdiens het die staat en die kommunisme gekom.

So dan bekamp die kommunisme die een euwel deur 'n ander in die plek daarvan te stel, want in die plek van die kapitalis het die verabsoluteerde staat gekom, met slegs dié verskil dat die mag van laasgenoemde veel verder strek en dieper ingryp in elke lewensfeer.

P.U. vir C.H.O.

J. D. van der Vyver, 